This item was submitted to Loughborough's Institutional Repository (https://dspace.lboro.ac.uk/) by the author and is made available under the following Creative Commons Licence conditions.

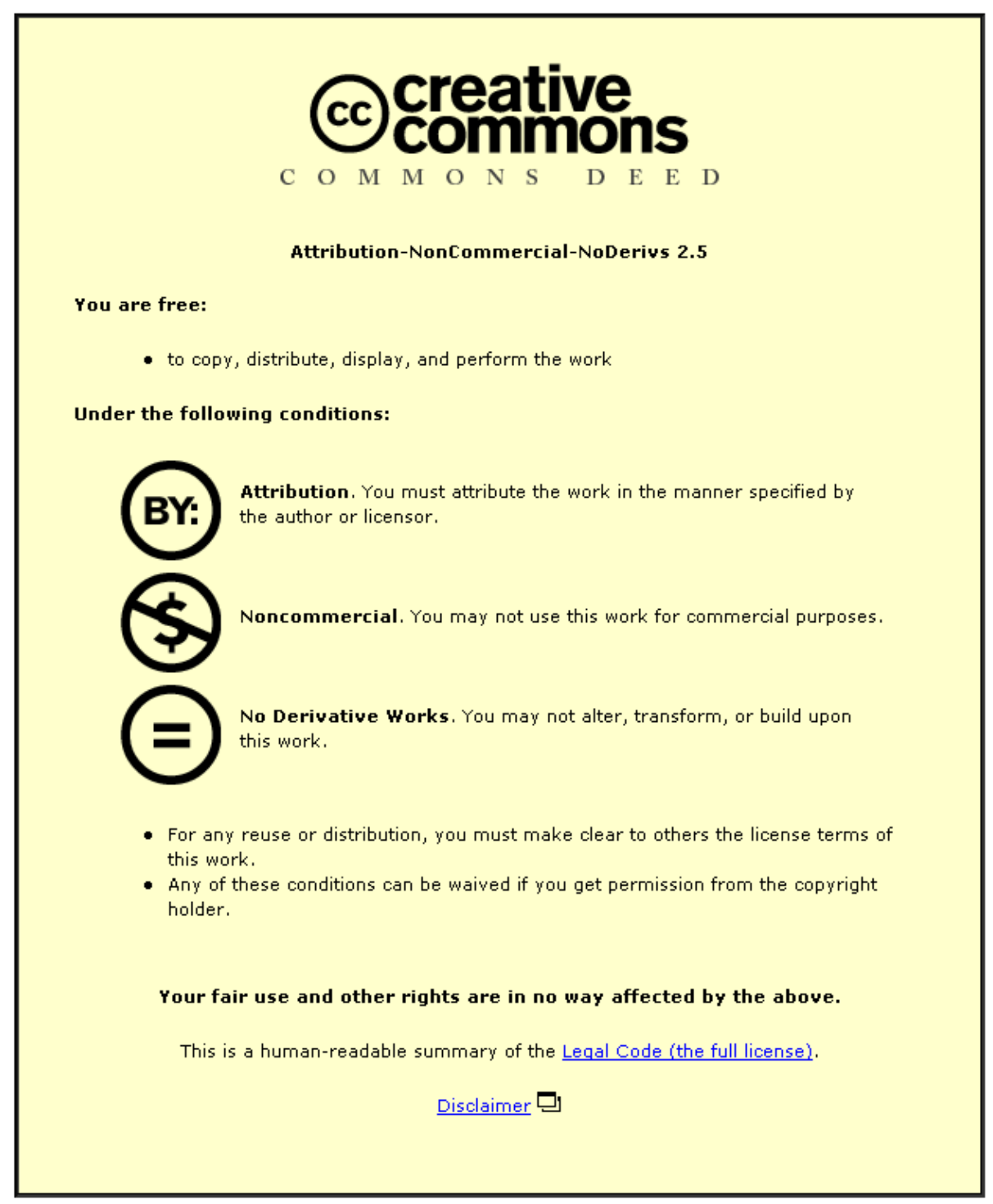

For the full text of this licence, please go to: http://creativecommons.org/licenses/by-nc-nd/2.5/ 


\title{
Determination of the bending stiffness for a spiral strand
}

\author{
M Raoof* and T J Davies \\ Department of Civil and Building Engineering, Loughborough University, Loughborough, Leicestershire, UK
}

\begin{abstract}
Owing to their peculiar construction, axially preloaded spiral strands undergo plane-section bending only for sufficiently small maximum lateral deflection/span ratios. Beyond a certain limit of this ratio, plane sections do not remain plane and, depending on the level of axial tension and imposed radius of curvature, interlayer slippage takes place, starting from the outer layer and spreading towards the centre of the strand. On the theoretical side, apart from one publication in the mid-1980s and some fairly recent publications by the first author and his associates, all other theoreticians have previously assumed either plane-section bending or, in many cases, have totally ignored the ever-present interwire friction, assuming that the individual helical wires act as simple helical springs. Previously reported experimental techniques, aimed at measuring the effective bending stiffness of helically wound cables, also largely suffer from major shortcomings. In the present paper, a novel experimental method is reported for obtaining reliable measurements of the effective bending stiffness of axially loaded spiral strands. It is very simple and relatively inexpensive to use in practice, for even very large (greater than, say, $100 \mathrm{~mm}$ outside diameter) spiral strands. Effective bending stiffness measurements, based on this approach, are reported here for a $164 \mathrm{~mm}$ outside diameter spiral strand (with axial loads of up to $3 \mathrm{MN}$ ), with these supported by a detailed theoretical analysis, which reinforces the generally sound nature of the proposed method.
\end{abstract}

Keywords: spiral strands, bending, stiffness, bridges, offshore platforms, guyed masts

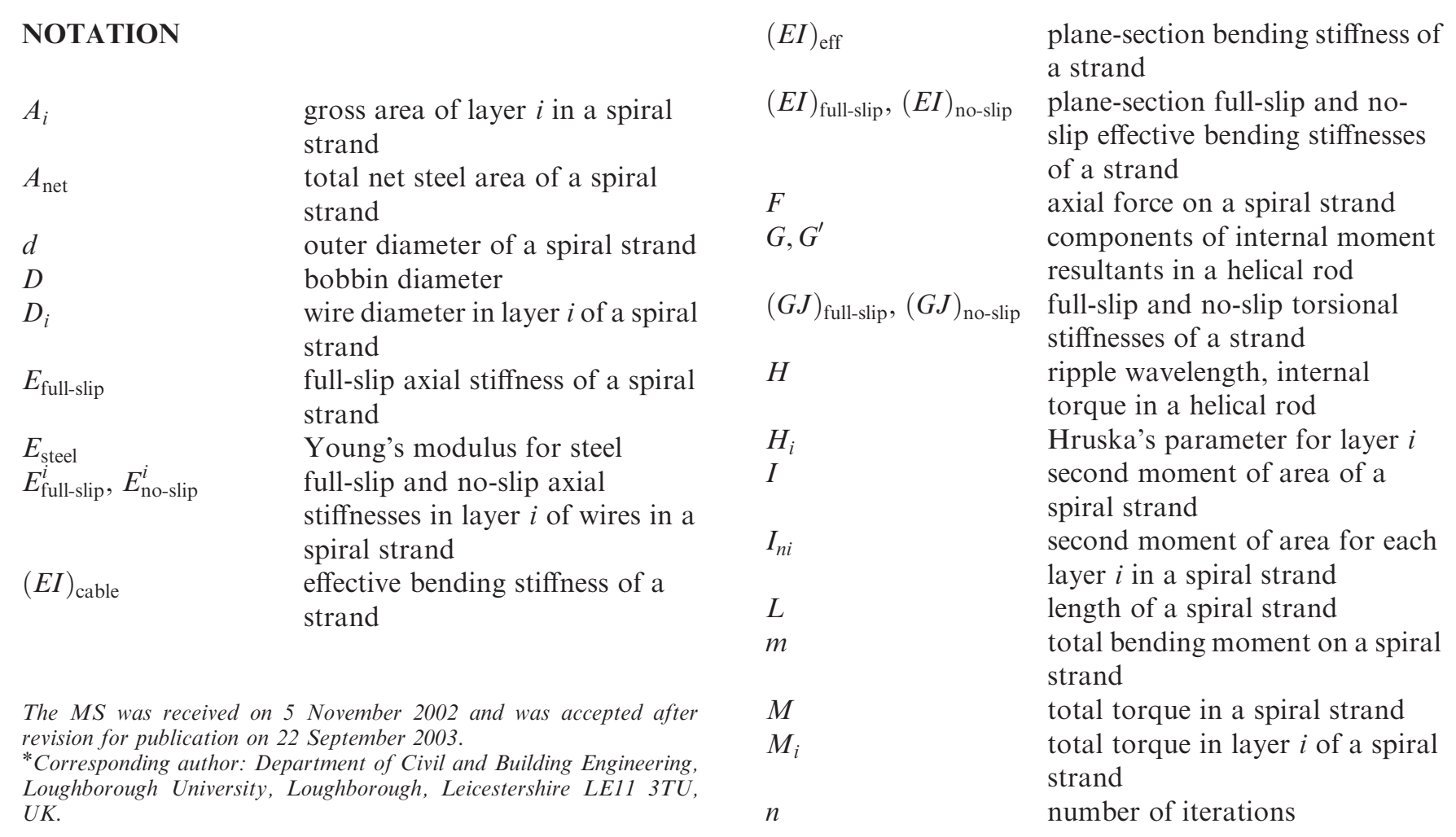

S05602 (C) IMechE 2004
J. Strain Analysis Vol. 39 No. 1 
$n_{i} \quad$ number of wires in layer $i$ of a spiral strand $N \quad$ total number of layers in a spiral strand

$N, N^{\prime}, T$ components of internal force resultants in a helical rod

$r \quad$ ripple amplitude ( $=$ half the ripple range)

$r_{i} \quad$ helix radius in layer $i$ of a spiral strand

$R \quad$ radius of curvature of a strand

$s \quad$ distance along the centre-line of a helical rod

$S_{1}^{\prime} \quad$ mean axial strain of a spiral strand

$T \quad$ axial tension in a helical rod

$\alpha$

lay angle of a spiral strand (or helical rod) in its deformed (corkscrew) state, lay angle of the helical wires in a spiral strand

$\Delta \quad$ change in the ripple wavelength resulting from an applied axial force

$\varepsilon_{\mathrm{h} 1} \quad$ axial strain in a helical cable

$\kappa_{0}, \kappa_{0}^{\prime} \quad$ initial curvatures of the centre-line of a helical rod

$\kappa_{1}, \kappa_{1}^{\prime} \quad$ final curvatures of the centre-line of a helical rod

$\tau_{i} \quad$ shear stress in layer $i$ of a spiral strand

$\tau_{0}, \tau_{1} \quad$ initial and final twists of the centre-line of a helical rod

\section{INTRODUCTION}

The strength of a spiral strand is derived principally from wires laid in a simple helical path around an underlying core. A large-diameter, multilayered spiral strand can have as many as 552 wires laid in, for example, eleven layers, giving an overall outside diameter of, say, $184 \mathrm{~mm}$ with an ultimate tensile strength of 27.65 MN. The fundamental purpose for the helical geometry is to provide bending flexibility and bundle coherence at the expense of some reductions in axial stiffness and tensile strength.

Spiral strands have played an indispensable role in various fields, including stays for guyed masts and bridging applications such as hangers for suspension bridges and the main cables of cable-stayed designs. The safety of many deep-water platform concepts, including tethered buoyant structures is, among other considerations, strongly dependent on the reliability of the mooring systems.

Until fairly recently, despite the efforts of research workers which date back to the early years of the last century, little light had been cast on the free-bending behaviour of helically wound cables taking interwire/ interlayer friction into account, where, in the present terminology, the term free bending refers to cases where the cable undergoes bending in the absence of sheaves, fairleads or other formers, so that the radius of curvature is not predetermined. There is little point in reporting a detailed review of previous literature here, as this has already been done in considerable detail elsewhere [1-4]. For the present purposes, it may, perhaps, suffice merely to mention a number of key issues of direct relevance to the question of determining the effective bending stiffness of a spiral strand under free-bending conditions - the subject of the present paper.

On the theoretical side, apart from one publication in the mid-1980s [5] and some fairly recent publications by the first author and his associates (e.g. references [1] to [3]), all other theoreticians have previously either assumed plane-section bending or, in many cases, have even completely ignored the ever-present interwire friction, assuming that the individual helical wires act as simple helical springs (e.g. reference [6]).

There are various experimental techniques, as discussed by Malinovsky [7], available for the determination of the effective bending stiffness of a helically wound steel cable. As mentioned by Malinovsky, in the course of numerous experiments with tensioned cables, the bending stiffness has been found to be heavily dependent upon the applied tension, and can vary between two limiting conditions, corresponding to either full or zero interlayer shear interaction of the wire elements in a helically wound cable. In the former case, the cable acts somewhat as a 'solid bar', with allowance made for the presence of helical voids; in the latter, the individual helical wires act independently and merely bend about their own neutral axes. For large-diameter multilayered spiral strands, the difference between the two limits is unacceptably large, being given approximately by the square of the strand/wire diameter ratio $[8]$.

The problem with the experimental determination of the effective bending stiffness is the discrepancy between the values of this parameter as determined by the different methods, which is mainly due to the experimental conditions and the level of imposed curvature. As reported in reference [7], for example, using a $34 \mathrm{~mm}$ outside diameter fibre-core wire rope, the bending stiffness was determined using two different methods, the frequency method and the method of static bending, and was found to be 3000 and $534 \mathrm{~N} \mathrm{~m}^{2}$ respectively. In other words, the difference between the experimental results was rather significant, with the value of the bending stiffness determined by the method of static bending being 0.18 times that determined using the frequency method.

For the bending of helically wound steel cables (spiral strands and wire ropes) under an approximately steady mean axial load, it is common to introduce a mathematically convenient constant effective bending stiffness for the cable, using which the radii of curvature at the points of restraint are then calculated. Owing to their peculiar construction, axially preloaded spiral strands undergo plane-section bending only for sufficiently small levels of strand maximum lateral deflection/span ratios. Beyond a certain limit of this ratio, plane sections do 
not remain plane and, depending on the level of axial tension and the imposed radius of curvature, interlayer slippage takes place, starting from the outer layer and spreading towards the centre of the strand $[3,5,9-11]$.

Large-scale free-bending experimental observations on axially preloaded $39 \mathrm{~mm}$ outside diameter spiral strands have been reported by Raoof [10, 11], who showed that, in the case of strands subjected to practical working ranges of axial load and laterally bent with large enough radii of curvature, it may be assumed that the strand cross-section remains plane during the bending cycle.

Raoof and Hobbs [8] have argued that, even with infinite shear stiffness between the layers of an axially preloaded multilayered spiral strand (i.e. assuming that plane sections remain plane during bending), linecontact interwire slippage within the wires in the individual layers, and hence some (although not very significant) reductions in the effective bending stiffness, $(E I)_{\text {cable }}$, of the strand, may still take place.

The purpose of the present paper is to report a simple but still more reliable method, compared with those described by, for example, Malinovsky [7], for experimentally obtaining the effective bending stiffness of axially loaded spiral strands. The experimentally determined bending stiffness for a $164 \mathrm{~mm}$ outside diameter spiral strand will, then, be backed by a detailed theoretical analysis, which reinforces the generally sound nature of the proposed method.

\section{EXPERIMENTAL MEASUREMENTS}

It was discovered, accidentally, that, by wrapping a $164 \mathrm{~mm}$ outside diameter spiral strand (with construction details given in Table 1) around a $5 \mathrm{~m}$ diameter bobbin ( $6 \mathrm{~m}$ combined cable and bobbin diameter) for transportation purposes, when the strand was unwrapped the shape of the strand was distorted because of the bobbin-strand diameter ratio, $D / d$, being too small, i.e. the strand was no longer straight (Fig. 1) but formed a helical 'corkscrew' shape. This happened with a bobbin-strand diameter ratio, $D / d$, approximately equal to $30(=5000 / 164)$.

In situ measurements related variations in the axial load on the spiral strand, $F$, to changes in the helical ripple range, $2 r$ (Fig. 1). The load on the strand was then removed and reapplied a number of times, following which the
Table 1 Construction details for the $164 \mathrm{~mm}$ outer diameter spiral strand

\begin{tabular}{lllll}
\hline $\begin{array}{l}\text { Layer, } \\
i\end{array}$ & $\begin{array}{l}\text { Number } \\
\text { of wires, } \\
n_{i}\end{array}$ & $\begin{array}{l}\text { Lay } \\
\text { direction* }\end{array}$ & $\begin{array}{l}\text { Wire } \\
\text { diameter, } \\
(\mathrm{mm})\end{array}$ & $\begin{array}{l}\text { Lay angle, } \alpha_{i} \\
(\mathrm{deg})\end{array}$ \\
\hline 1 & 72 & $\mathrm{RH}$ & 6.5 & 18.01 \\
2 & 66 & LH & 6.5 & 18.01 \\
3 & 60 & $\mathrm{RH}$ & 6.5 & 18.01 \\
4 & 54 & LH & 6.5 & 18.01 \\
5 & 48 & $\mathrm{RH}$ & 6.5 & 18.01 \\
6 & 42 & LH & 6.5 & 18.01 \\
7 & 36 & $\mathrm{RH}$ & 6.6 & 18.01 \\
8 & 30 & LH & 6.6 & 18.01 \\
9 & 24 & $\mathrm{RH}$ & 6.6 & 18.01 \\
10 & 18 & LH & 6.6 & 18.01 \\
& & & & 17.99 \\
Core & 14 & N/A & 6.0 & 12.98 and 12.15 \\
& $7+7$ & N/A & 3.70 and 4.85 & \\
& 7 & N/A & 4.95 & - \\
& 1 & N/A & 6.70 &
\end{tabular}

${ }^{*} \mathrm{RH}$, right-hand lay; $\mathrm{LH}$, left-hand lay.

relationship between the axial load on the strand and the ripple range corresponding to a final loading run was again obtained. Figure 2 presents the obtained plots of axial load versus ripple range, for both the first and final loading runs, with the individual test data points exhibiting (over the experimental range) practically reasonable scatter about the fitted straight lines.

\section{THEORY}

\subsection{Distorted shape of the strand-simplified method}

The simplified theory is, as the name suggests, a simple method for determining the effective bending stiffness of a spiral strand, $(E I)_{\text {cable }}$, based on the relationship between the axial force, $F$, and the ripple range, $2 r$ (Fig. 2). As will be explained later, this approach also makes it possible reasonably to extrapolate the results, such as those presented in Fig. 2, to regions where no test data are available.

Figure 3 shows the planar geometry of the spiral strand used in the simplified analysis, where a helix may always be unwrapped to form a right-angled triangle. The helix lay angle, $\alpha$, in Fig. 3 is

$$
\alpha=\tan ^{-1}\left(\frac{2 \pi r}{H}\right)
$$

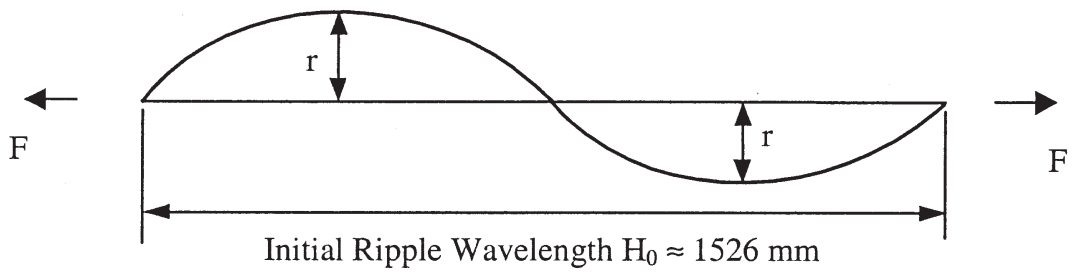

Fig. 1 Observed distorted (corkscrew) shape of the $164 \mathrm{~mm}$ outside diameter spiral strand subjected to an axial force, $F$ 


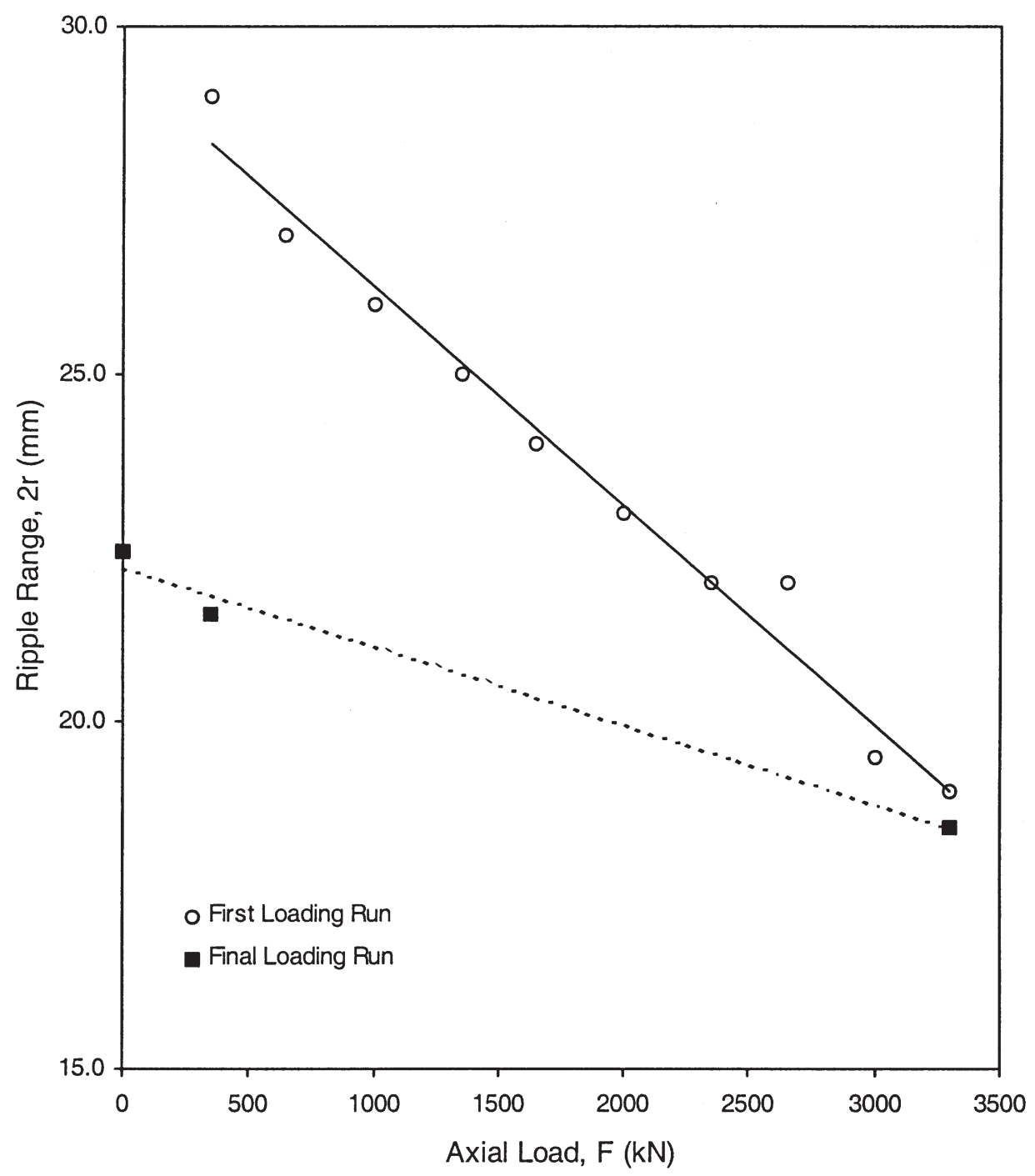

Fig. 2 Variations in the ripple range, $2 r$, with changes in the externally applied axial force, $F$, for both the first and final loading runs

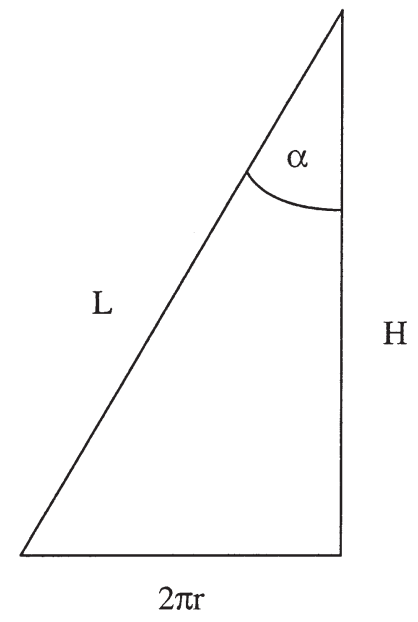

Fig. 3 Planar representation of the helical cable used in the simplified analysis where $H$ is the measured ripple wavelength and $r$ is the corresponding amplitude of the ripple in the test specimen. Once $\alpha$ has been calculated, the value of the radius of curvature, $R$, for the helix can be determined from

$$
R=\frac{r}{\sin ^{2} \alpha}
$$

as can the bending moment, $m$, using

$$
m=F \times r
$$

The effective bending stiffness of the axially loaded spiral strand, $(E I)_{\text {cable, }}$ is, then, quite simply, the slope of the bending moment, $m$, against curvature, $1 / R$, plots. This simple approach, however, assumes that the contributions from other internal moments and forces, in the so-called helical rod (cable), are sufficiently small to be neglected, and that $H=H_{0}$ over the full range of axial force, $F$, where $H_{0}$ is the initial value of the wavelength. 
A justification for these assumptions forms the main purpose of the next section, where a more rigorous approach is presented, which takes all of the possible internal force and moment actions into account, while the wavelength, $H$, is allowed to vary as a function of changes in $F$, in arriving at a more exact relationship between the axial force, $F$, and the ripple range, $2 r$. Comparisons between the $F$ versus $2 r$ plots based on the simple and the more rigorous approaches, will, then, clarify the practical implications of ignoring the possible influence of a number of internal forces and couples as well as variations in the wavelength, $H$, in the simplified approach.

\subsection{Distorted shape of the strand-rigorous method}

Love [12] has presented equilibrium equations for the solution to the problem of a helical spring subjected to an axial force and a twisting moment. In Love's approach, the spring is treated as a thin curved rod that satisfies the six non-linear equations of equilibrium. As an axial force is applied to the spring, the lay angle changes, as does the helix radius of the spring. Blanco and Costello [13] used Love's equations to determine the changes in various structural characteristics of the spring as controlled by an internal cylindrical constraint, neglecting friction between the spring and the internal cylinder. The formulations of Love and of Blanco and Costello are used as the basis for the following developments.

Initially, when there is zero axial load, $F$, on the cable, the relationship between the initial ripple range, $2 r_{0}$, and the initial ripple wavelength, $H_{0}$, can be described, schematically, by Fig. 4a, where, for the first loading run, $r_{0}=15 \mathrm{~mm}$ (Fig. 2). Using simple trigonometry, the following relationships are established:

$$
\begin{aligned}
& \sin \alpha_{0}=\frac{2 \pi r_{0}}{L_{0}} \\
& L_{0}=\sqrt{\left(2 \pi r_{0}\right)^{2}+\left(H_{0}\right)^{2}}
\end{aligned}
$$

When an axial force, $F$, is applied to the cable, as in Fig. 1, it deforms in such a way that the relationship between the ripple range and the ripple wavelength, for the helical rod, is defined as in Fig. 4b.

Once again, using simple trigonometry, the relationships between the geometrical parameters in Fig. $4 \mathrm{~b}$ are established as

$$
\begin{aligned}
& \sin \alpha_{1}=\frac{2 \pi r_{1}}{L_{0}\left(1+\varepsilon_{\mathrm{h} 1}\right)} \\
& L_{0}\left(1+\varepsilon_{\mathrm{h} 1}\right)=\sqrt{\left(2 \pi r_{1}\right)^{2}+\left(H_{0}+\Delta\right)^{2}}
\end{aligned}
$$

and, denoting the axial tension in the cable as $T$,

$$
T=E_{\text {full-slip }} \times A_{\text {net }} \times \varepsilon_{\mathrm{h} 1}
$$

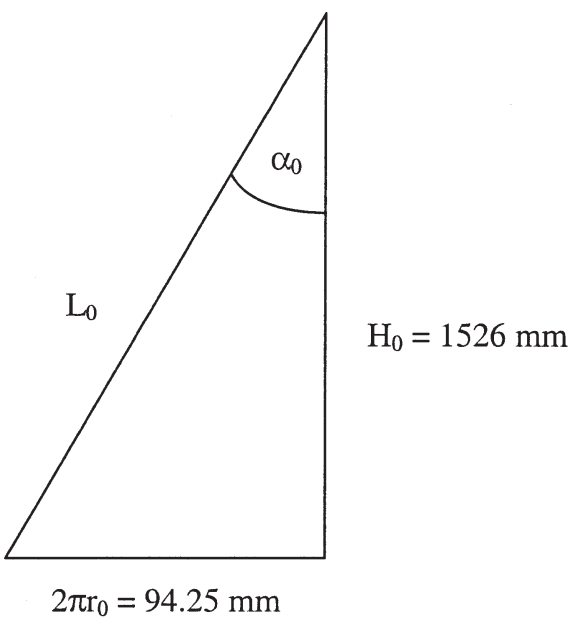

(a)

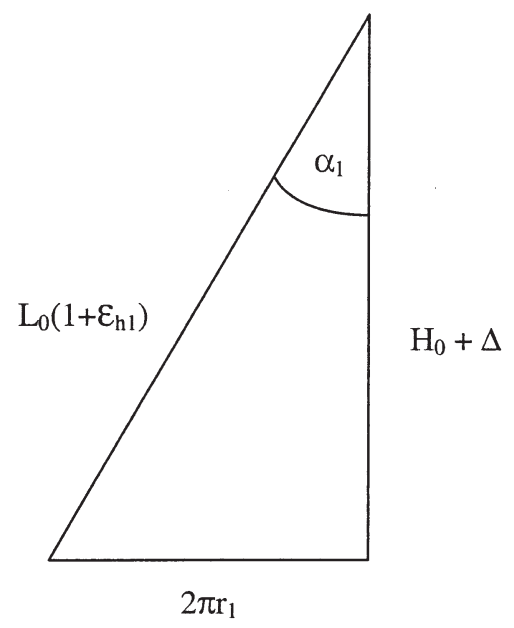

(b)

Fig. 4 (a) Schematic representation of the helical cable under zero axial load, based on the first loading run; (b) schematic representation of the helical cable under an externally applied axial load

where $\varepsilon_{\mathrm{h} 1}$ is the axial strain in the cable resulting from the applied axial force $F, \Delta$ is the change in the ripple wavelength resulting from the applied axial force, $r_{1}$ is the new ripple amplitude and $A_{\text {net }}$ is the net steel area of the helical cable [14]. The full-slip Young's modulus of the cable, $E_{\text {full-slip }}$, is given by either the simple formulations previously reported by Raoof [15] or, more accurately, by the fairly complex orthotropic sheet theoretical model of Hobbs and Raoof [14].

The equations of equilibrium for a thin rod are given by Love [12] as

$$
\begin{aligned}
& \frac{\mathrm{d} N}{\mathrm{~d} s}-N^{\prime} \tau_{1}+T \kappa_{1}^{\prime}+X=0 \\
& \frac{\mathrm{d} N^{\prime}}{\mathrm{d} s}-T \kappa_{1}+N \tau_{1}+Y=0 \\
& \frac{\mathrm{d} T}{\mathrm{~d} s}-N \kappa_{1}^{\prime}+N^{\prime} \kappa_{1}+Z=0
\end{aligned}
$$




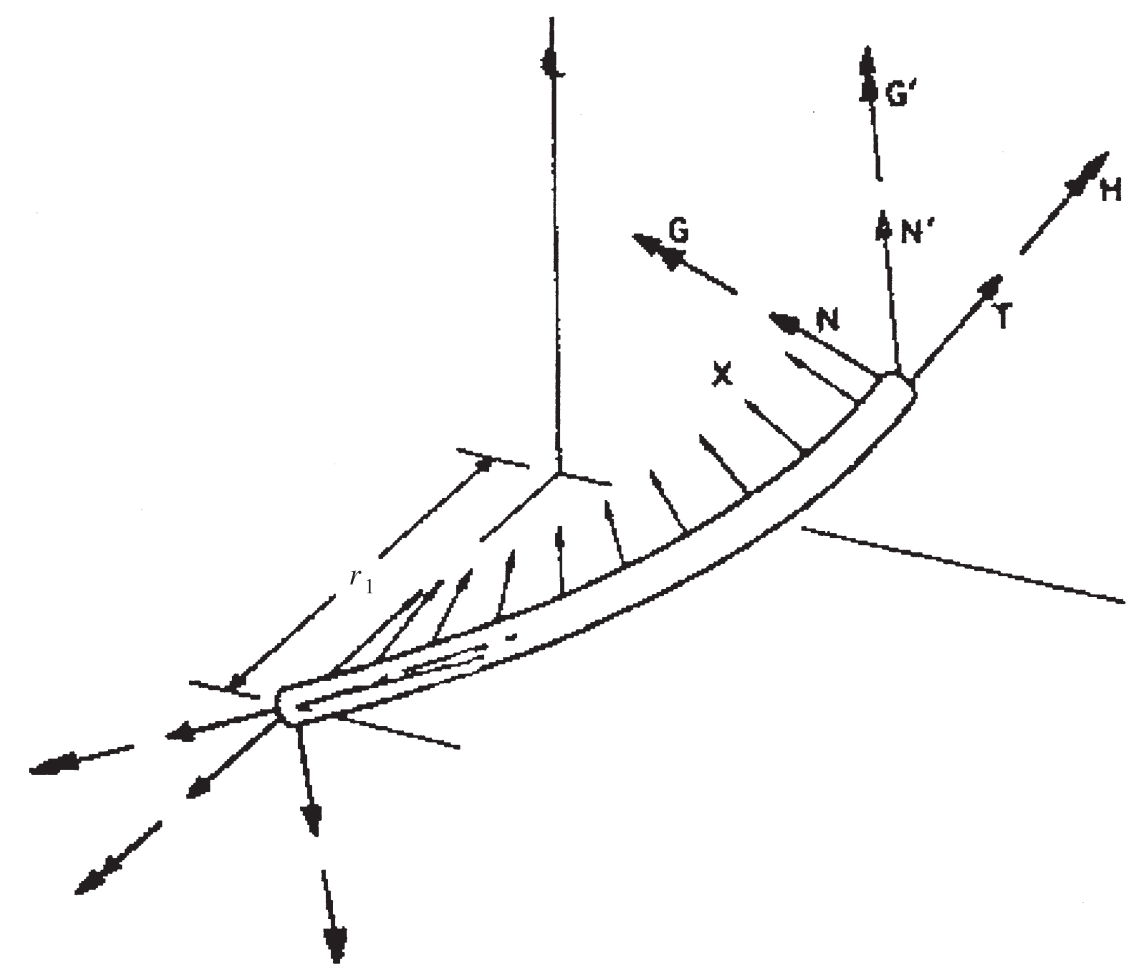

Fig. 5 External and internal forces and moments acting on the helical rod. (After reference [13])

$$
\begin{aligned}
& \frac{\mathrm{d} G}{\mathrm{~d} s}-G^{\prime} \tau_{1}+H \kappa_{1}^{\prime}-N^{\prime}+K=0 \\
& \frac{\mathrm{d} G^{\prime}}{\mathrm{d} s}-H \kappa_{1}+G \tau_{1}+N+K^{\prime}=0 \\
& \frac{\mathrm{d} H}{\mathrm{~d} s}-G \kappa_{1}^{\prime}+G^{\prime} \kappa_{1}+\theta=0
\end{aligned}
$$

where $s$ is the distance along the centre-line of the rod, $\kappa_{1}$ and $\kappa_{1}^{\prime}$ are the components of the final curvatures, $\tau_{1}$ is the final twist and $X, Y, Z, K, K^{\prime}$ and $\theta$ are the components of the external forces and couple-resultants per unit length along the rod, with $N, N^{\prime}, T, G, G^{\prime}$ and $H$ being the components of the internal forces and couple-resultants of the helical rod in the normal, binormal and tangential directions (Fig. 5). For the helical rod, the bending and twisting couples, $G, G^{\prime}$ and $H$, are related to the initial curvatures, $\kappa_{0}$ and $\kappa_{0}^{\prime}$, and the initial twist, $\tau_{0}$, by

$$
\begin{aligned}
& G=(E I)_{\text {full-slip }}\left(\kappa_{1}-\kappa_{0}\right) \\
& G^{\prime}=(E I)_{\text {full-slip }}\left(\kappa_{1}^{\prime}-\kappa_{0}^{\prime}\right) \\
& H=(G J)_{\text {full-slip }}\left(\tau_{1}-\tau_{0}\right)
\end{aligned}
$$

where $(E I)_{\text {full-slip }}$ is the full-slip plane-section bending stiffness of the cable, obtained for a specific spiral strand, with a reasonably high degree of accuracy, by the method described by Raoof and Hobbs [8], or less accurately, but good enough for most practical purposes, by the method proposed by Raoof $[15] ;(G J)_{\text {full-slip }}$ is the full-slip torsional stiffness of the strand, and can be calculated using the method described by Raoof and Hobbs [16].

For the helical rod, the initial curvatures, $\kappa_{0}$ and $\kappa_{0}^{\prime}$, and twist, $\tau_{0}$, are given by

$$
\begin{aligned}
\kappa_{0} & =0 \\
\kappa_{0}^{\prime} & =\frac{\sin ^{2} \alpha_{0}}{r_{0}} \\
\tau_{0} & =\frac{\sin \alpha_{0} \cos \alpha_{0}}{r_{0}}
\end{aligned}
$$

where $\alpha_{0}$ and $r_{0}$ are the initial lay angle and helix radius of the rod respectively, corresponding to an axial force $F=0$. When an axial force, $F$, is applied to the rod (Fig. 1), the final (deformed) curvatures and twist are given by

$$
\begin{aligned}
\kappa_{1} & =0 \\
\kappa_{1}^{\prime} & =\frac{\sin ^{2} \alpha_{1}}{r_{1}} \\
\tau_{1} & =\frac{\sin \alpha_{1} \cos \alpha_{1}}{r_{1}}
\end{aligned}
$$

where $\alpha_{1}$ and $r_{1}$ are the lay angle and helix radius of the deformed rod respectively under an applied axial force, $F$. It is assumed that there is zero friction along the surface of the helical rod, and that the external bending moments $K$ and $K^{\prime}$ are both equal to zero, with $X=0$. 
As such, for a constant tension $T$ along the length of the rod, equations (9) to (14) become [13]

$$
\begin{aligned}
& -N^{\prime} \tau_{1}+T \kappa_{1}^{\prime}=0 \\
& Y=0 \\
& Z=0 \\
& -G^{\prime} \tau_{1}+H \kappa_{1}^{\prime}-N^{\prime}=0 \\
& N=0 \\
& \theta=0
\end{aligned}
$$

As explained next, equations (4) to (29) provide a simple means of predicting the variations in the ripple amplitude, $r_{1}$, as a function of changes in the externally applied force, $F$.

Using equations (22) to (24),

$$
-N^{\prime} \frac{\sin \alpha_{1} \cos \alpha_{1}}{r_{1}}+T \frac{\sin ^{2} \alpha_{1}}{r_{1}}=0
$$

Similarly, using equations (22), (23) and (27),

$$
N^{\prime}=-G^{\prime} \frac{\sin \alpha_{1} \cos \alpha_{1}}{r_{1}}+H \frac{\sin ^{2} \alpha_{1}}{r_{1}}
$$

where

$$
G^{\prime}=(E I)_{\text {full-slip }}\left(\frac{\sin ^{2} \alpha_{1}}{r_{1}}-\frac{\sin ^{2} \alpha_{0}}{r_{0}}\right)
$$

and

$$
H=(G J)_{\text {full-slip }}\left(\frac{\sin \alpha_{1} \cos \alpha_{1}}{r_{1}}-\frac{\sin \alpha_{0} \cos \alpha_{0}}{r_{0}}\right)
$$

Using equations (31) to (33) yields

$$
\begin{aligned}
N^{\prime}= & -(E I)_{\text {full-slip }}\left(\frac{\sin ^{2} \alpha_{1}}{r_{1}}-\frac{\sin ^{2} \alpha_{0}}{r_{0}}\right) \frac{\sin \alpha_{1} \cos \alpha_{1}}{r_{1}} \\
& +(G J)_{\text {full-slip }}\left(\frac{\sin \alpha_{1} \cos \alpha_{1}}{r_{1}}-\frac{\sin \alpha_{0} \cos \alpha_{0}}{r_{0}}\right) \\
& \times \frac{\sin ^{2} \alpha_{1}}{r_{1}}
\end{aligned}
$$

From equation (30), $N^{\prime}$ is given as

$$
N^{\prime}=T \tan \alpha_{1}
$$

while, from the force equilibrium [13],

$$
F=T \cos \alpha_{1}+N^{\prime} \sin \alpha_{1}
$$

From equations (35) and (36),

$$
\cos \alpha_{1}=\frac{T}{F}
$$

and

$$
N^{\prime}=F \sin \alpha_{1}
$$

Equations (34) and (38) give the magnitude of the applied axial force, $F$, as

$$
\begin{aligned}
F= & -(E I)_{\text {full-slip }}\left(\frac{\sin ^{2} \alpha_{1}}{r_{1}}-\frac{\sin ^{2} \alpha_{0}}{r_{0}}\right) \frac{\cos \alpha_{1}}{r_{1}} \\
& +(G J)_{\text {full-slip }}\left(\frac{\sin \alpha_{1} \cos \alpha_{1}}{r_{1}}-\frac{\sin \alpha_{0} \cos \alpha_{0}}{r_{0}}\right) \\
& \times \frac{\sin \alpha_{1}}{r_{1}}
\end{aligned}
$$

By combining equations (6), (8) and (37), $r_{1}$ is given by

$$
r_{1}=\frac{\sin \alpha_{1}\left\{L_{0}\left[1+\left(F \cos \alpha_{1}\right) /\left(E_{\text {full-slip }} \times A_{\text {net }}\right)\right]\right\}}{2 \pi}
$$

Finally, the next two subsections discuss means of providing the essential full-slip $E I$ and $G J$ values as input into the 'more exact' calculations.

\subsubsection{Calculation of the plane-section bending stiffness, (EI) eff}

The theoretical full-slip and no-slip plane-section bending stiffnesses, $(E I)_{\text {full-slip }}$ and $(E I)_{\text {no-slip }}$, for a spiral strand may be calculated using the procedure developed by Raoof [15]. For each individual layer $i$, Hruska's parameter, $H_{i}$, is calculated from the equation

$$
H_{i}=\cos ^{4} \alpha_{i}
$$

The full-slip orthotropic $E$ values for the individual layers $i, E_{i}^{\text {full-slip }}$, are given by

$$
\begin{aligned}
\frac{E_{i}^{\text {full-slip }}}{E_{\text {steel }}}= & -0.26442-2.004046 H_{i}+6.5735 H_{i}^{2} \\
& -3.3068 H_{i}^{3}, \quad 0.70 \leqslant H_{i} \leqslant 1.0
\end{aligned}
$$

where the Young's modulus for steel $E_{\text {steel }}=200 \mathrm{kN} /$ $\mathrm{mm}^{2}$.

The corresponding no-slip $E$ values for the individual layers $i$ may be obtained from

$$
\begin{gathered}
\frac{E_{i}^{\text {no-slip }}}{E_{i}^{\text {full-slip }}}=3.998-7.916 K_{1}+7.238 K_{1}^{2}-2.321 K_{1}^{3}, \\
0.35 \leqslant K_{1} \leqslant 1.0
\end{gathered}
$$

where

$$
K_{1}=\frac{E_{i}^{\text {full-slip }}}{E_{\text {steel }}}
$$




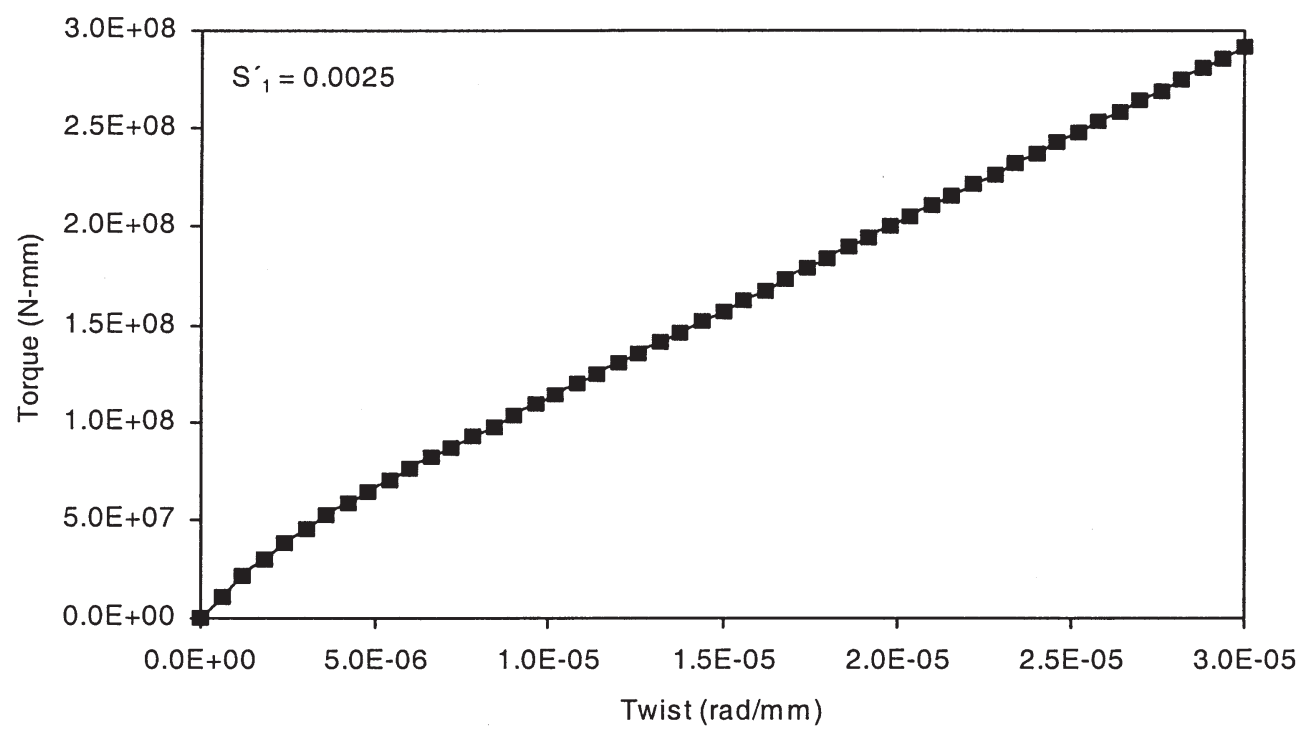

Fig. 6 Torque-twist relationship for the $164 \mathrm{~mm}$ outside diameter axially preloaded spiral strand at a mean axial strain $S_{1}^{\prime}=0.0025$

The next stage is to calculate the second moment of area for each layer, $I_{n i}$, where

$$
I_{n i}=\left[\frac{\pi}{4}\right] \times\left[\frac{\pi}{64}\right] \times\left[\left(2 r_{i}+D_{i}\right)^{4}-\left(2 r_{i}-D_{i}\right)^{4}\right]
$$

In the above, $r_{i}$ and $D_{i}$ are respectively the theoretical helix radius and the wire diameter in layer $i$. For each layer $i$,

$$
\lambda_{i}=\frac{I_{n i}}{I_{0}}
$$

where

$$
I_{0}=\sum_{i=1}^{N} I_{n i}
$$

with a total number of $N$ layers of helical wires in the strand.

The effective plane-section bending stiffness, $(E I)_{\text {eff, }}$, for either the full-slip or no-slip limiting conditions is, finally, given by

$$
(E I)_{\mathrm{eff}}=I \sum_{i=1}^{N} \lambda_{i} E_{i}
$$

where, denoting the strand outside diameter by $d$,

$$
I=\frac{\pi}{4}\left(\frac{\pi d^{4}}{64}\right)
$$

\subsubsection{Calculation of the torsional stiffness, (GJ)}

Very briefly, for any twist per unit length, the layer contributes a torque, $M_{i}$, to the total torque, $M$, on the spiral strand, where, following Raoof and Hobbs [16],

$$
M_{i}=\tau_{i} A_{i} r_{i}
$$

and

$$
M=\sum_{i=1}^{N} M_{i}+M_{\text {core }}
$$

In the above, $\tau_{i}$ is the layer shear stress, $r_{i}$ is the helix radius of the wires and $A_{i}$ is the gross area of a layer of wires, with the subscripts $i$ referring to layer $i$ in the spiral strand with a total number of $N$ layers of helical wires; $M_{\text {core }}$ is the torque in the straight central wirethe king wire.

At large torques, the behaviour of the spiral strand is dominated by large slipping movements along the line contacts (full slip), while at small torques (in the region close to the origin) the behaviour of the strand is dominated by the no-slip limiting condition (Fig. 6). By taking a tangent to the torque against twist per unit length plot in Fig. 6 at large torque values, the value of $(G J)_{\text {full-slip }}$ is obtained. Alternatively, by taking a tangent to the torque-twist curve at small torques (in the vicinity of the origin), the value of $(G J)_{\text {no-slip }}$ may be determined. As discussed elsewhere [16], the torque-twist per unit length plot is a function of the mean axial strain of the strand, although, unlike $(G J)_{\text {no-slip }},(G J)_{\text {full-slip }}$ is, for all practical purposes, independent of the level of axial preload on the strand.

\subsubsection{Solution procedure}

For given values of $r_{0}$ and $H_{0}$ (hence, $L_{0}$ and $\alpha_{0}$ as determined by equations (5) and (4) respectively), an initial value of $\alpha_{1}=\alpha_{0}$ may be assumed, and, by employing the Newton-Raphson iterative procedure, equations 


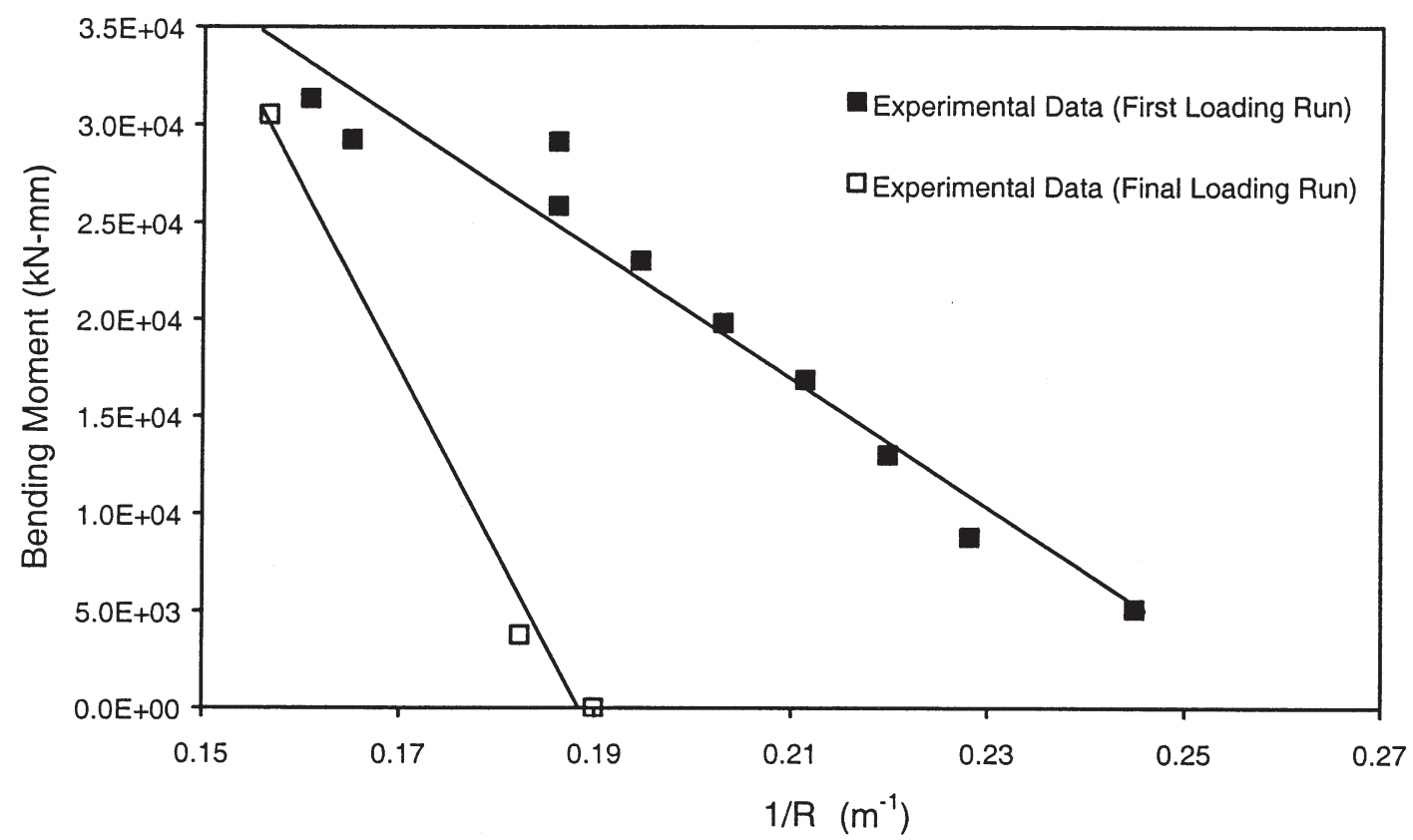

Fig. 7 Variations, based on the simplified approach, of the bending moment, $m$, as a function of the parameter $1 / R$

$(6),(8),(37),(39)$ and (40) [with the theoretical $(E I)_{\text {full-slip }}$ and $(G J)_{\text {full-slip }}$ values, discussed in the last two subsections, used as inputs] provide predictions of the amplitude of the ripple, $r_{1}$, for any given externally applied axial force, $F$. In the present work, the iterations were stopped when $\left|\alpha_{n+1}-\alpha_{n}\right| \leqslant 0.00000001 \mathrm{rad}$, where subscript $n$ refers to the number of iterations.

\section{RESULTS}

Figure 7 presents variations, based on the simplified approach, of the bending moment, $m$, as a function of changes in $1 / R$, where $R$ is the radius of curvature, over the full experimental range of axial force, $F$, and its associated values of $r$. For a detailed set of numerical results, corresponding to each individual calculation step, the interested reader may refer to the tables given in reference [4]. The effective bending stiffness, based on the experimental data, which is the slope of the plots in Fig. 7, may, then, be determined. Table 2 presents the values of the obtained effective cable bending stiffnesses, $(E I)_{\text {cable }}$, for both the first and final loading

Table 2 Values of the bending and torsional stiffnesses for the $164 \mathrm{~mm}$ outside diameter spiral strand

\begin{tabular}{ll}
\hline First loading run $(E I)_{\text {cable }}$ & $3.611 \times 10^{11} \mathrm{~N} \mathrm{~mm}^{2}$ \\
Final loading run $(E I)_{\text {cable }}$ & $9.48 \times 10^{11} \mathrm{~N} \mathrm{~mm}^{2}$ \\
Plane-section $(E I)_{\text {full-slip }}$ & $3.74 \times 10^{12} \mathrm{~N} \mathrm{~mm}^{2}$ \\
Plane-section $(E I)_{\text {no-slip }}$ & $4.59 \times 10^{12} \mathrm{~N} \mathrm{~mm}^{2}$ \\
$(G J)_{\text {full-slip }}$ & $8.31 \times 10^{11} \mathrm{~N} \mathrm{~mm}^{2}$ \\
$(G J)_{\text {no-slip }}$ & $1.77 \times 10^{12} \mathrm{~N} \mathrm{~mm}^{2}$ \\
\hline
\end{tabular}

runs, the theoretical plane-section bending stiffnesses, $(E I)_{\text {full-slip }}$ and $(E I)_{\text {no-slip, as calculated using equations }}$ (41) to (49), and the torsional stiffnesses, $(G J)_{\text {full-slip }}$ and $(G J)_{\text {no-slip }}$, as calculated using the method described by Raoof and Hobbs [16], where $(G J)_{\text {no-slip }}$ corresponds to a strand mean axial strain $S_{1}^{\prime}=0.0025$.

Using equations (1) to (3), in conjunction with the experimentally determined values of $(E I)_{\text {cable }}$ (corresponding to either the first or final loading run) as given in Table 2, and assuming $H=H_{0}=1526 \mathrm{~mm}$, predictions, based on the simplified method, of the curvature, $1 / R$, and hence, axial force, $F$, outside the original experimental range can be made for any given ripple range, $2 r$ (Fig. 8); in detail, the calculation steps are as follows:

1. For a given $r$, and assuming $H=H_{0}$, calculate $\alpha$ from equation (1).

2. For the given $r$ and calculated $\alpha$, use equation (2) to calculate $R$.

3. For the given $\alpha_{0}$ and $r_{0}$, use equation (2) to calculate $R_{0}$, where subscript 0 relates to the case when $F=0$, with the corresponding wavelength being $H_{0}$.

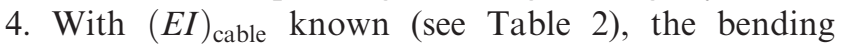
moment, $m$, is given by

$$
m=\left(\frac{1}{R}-\frac{1}{R_{0}}\right)(E I)_{\text {cable }}
$$

5. The axial force, $F$, is then given by equation (3).

It should be noted at once that, for the plots of $F$ versus $2 r$, based on the simplified method, in Fig. 8, the appropriate constant value of $(E I)_{\text {cable }}$ (corresponding to either 


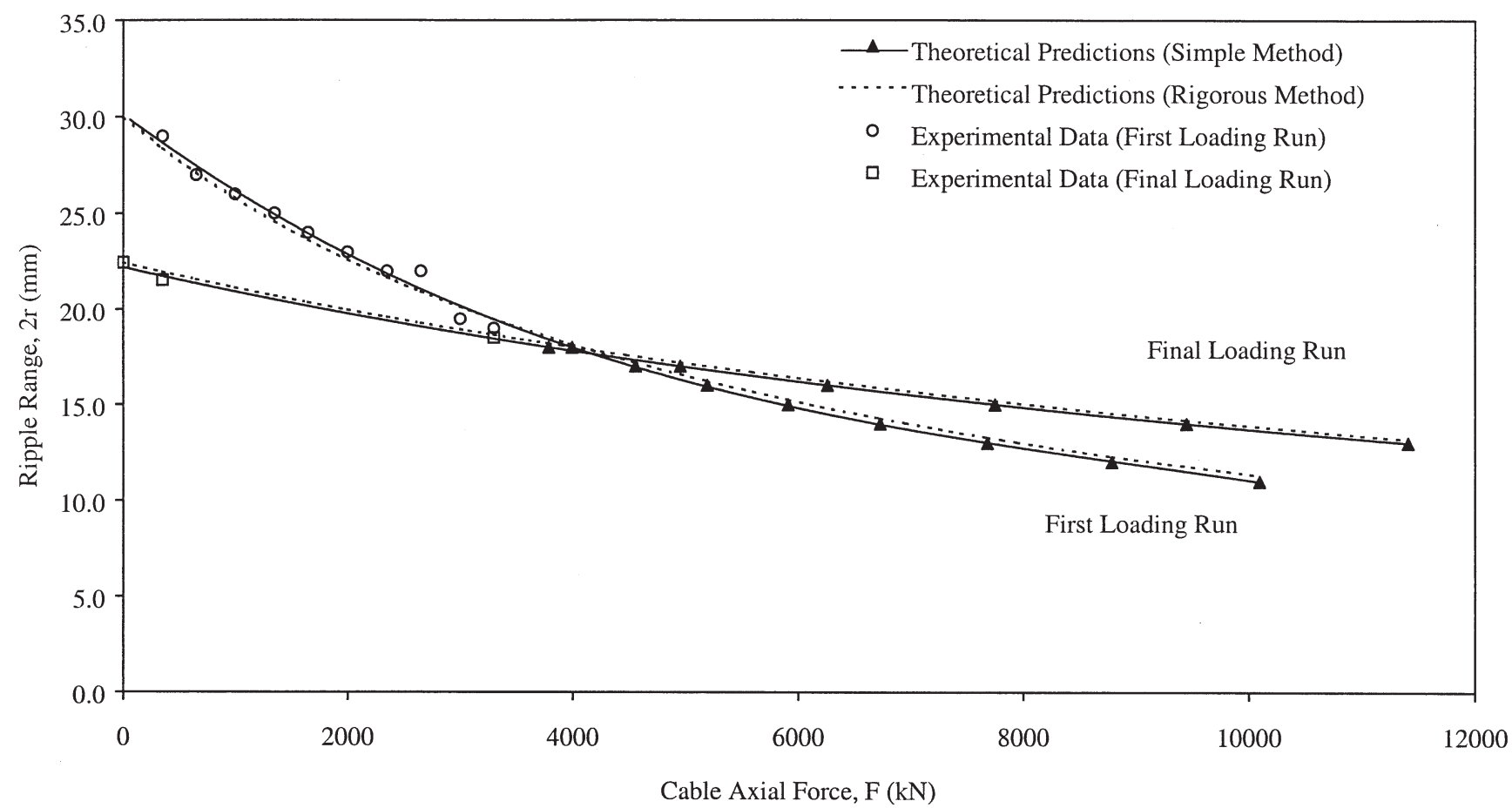

Fig. 8 Experimental as well as theoretical variations of the ripple range, $2 r$, with changes in the externally applied axial force, $F$, based on both the simplified and rigorous methods $\left(H_{0}=1526 \mathrm{~mm}\right.$ for both the first and final loading runs)

the first or the final loading run) has been assumed over the full range of each plot.

Using equations (6), (8), (37), (39) and (40), with the predicted $(E I)_{\text {full-slip }}$ and $(G J)_{\text {full-slip }}$ values (as given in Table 2) used as part of the input, predictions, based on the rigorous method, of the ripple range, $2 r$, can be made for any given axial force, $F$. Figure 8 shows the variations in the ripple range with changes in the applied axial force for both the experimental data and the theoretical predictions, based on both the simplified

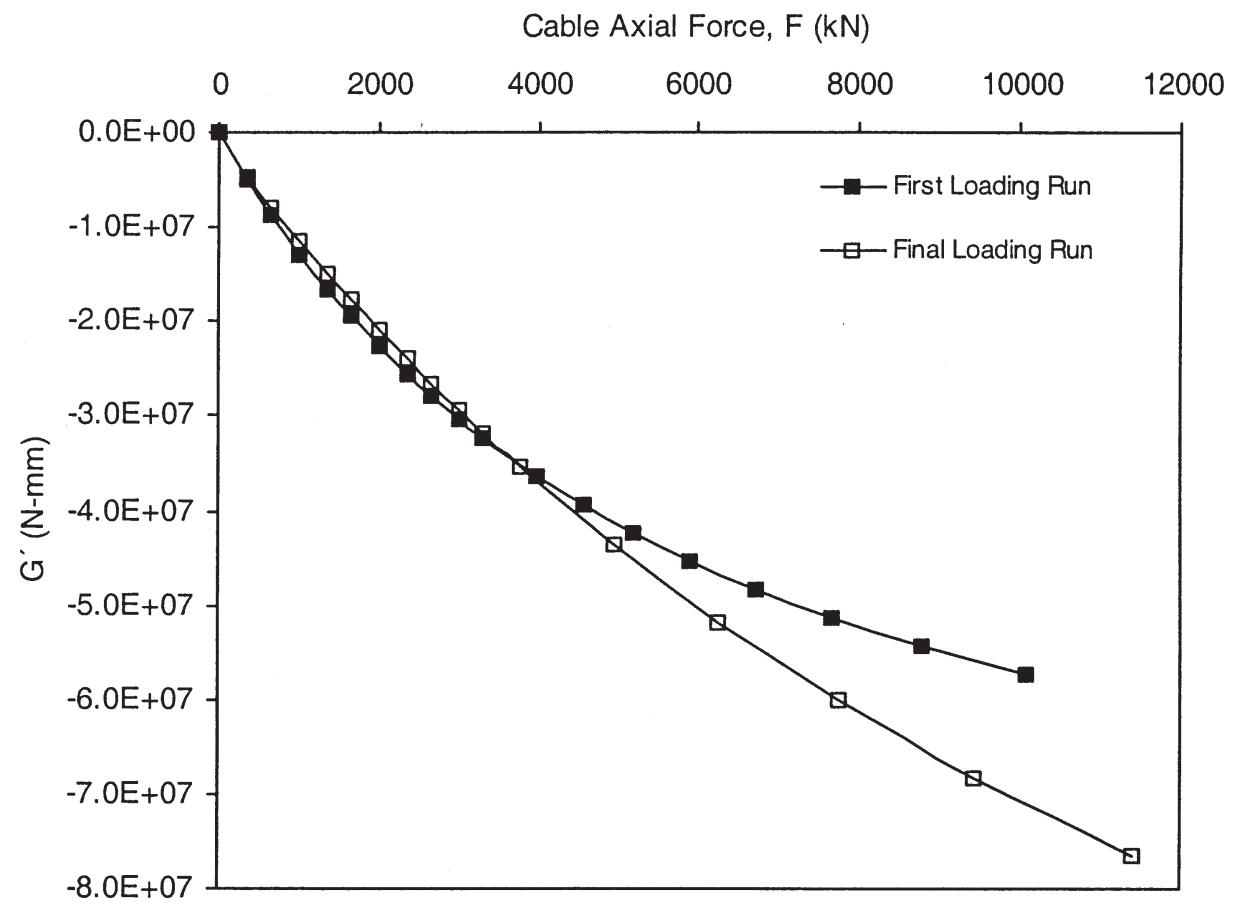

Fig. 9 Theoretical variations in parameter $G^{\prime}$ with changes in the externally applied axial force, $F$, for both the first and final loading runs 


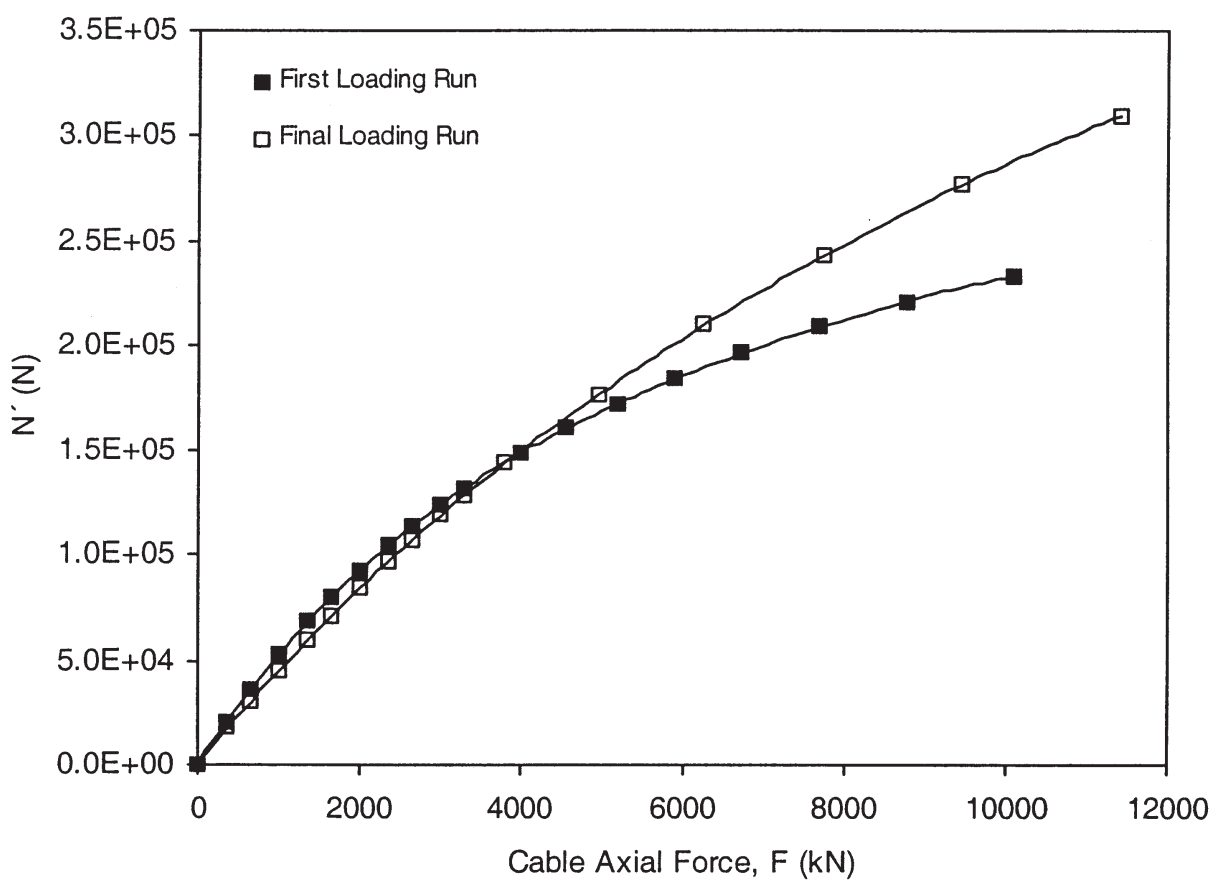

Fig. 10 Theoretical variations in the cable shear force, $N^{\prime}$, with changes in the externally applied axial force, $F$, for both the first and final loading runs

and rigorous methods. For a detailed set of numerical results, corresponding to each individual calculation step in the rigorous method, the interested reader may refer to the tables given in reference [4]. The variation in the bending moment, $G^{\prime}$, as well as the shear force, $N^{\prime}$, with changes in the applied axial force, based on the rigorous method, are shown graphically, for the first and final loading runs, in Figs 9 and 10 respectively. Estimated variations in the axial strain in the spiral strand, $\varepsilon_{\mathrm{h} 1}$, with changes in the applied axial force, $F$, and the theoretical predictions of changes in the ripple wavelength, $\Delta$, versus $F$, for both the first and final loading runs, are presented in Figs 11 and 12, respectively.

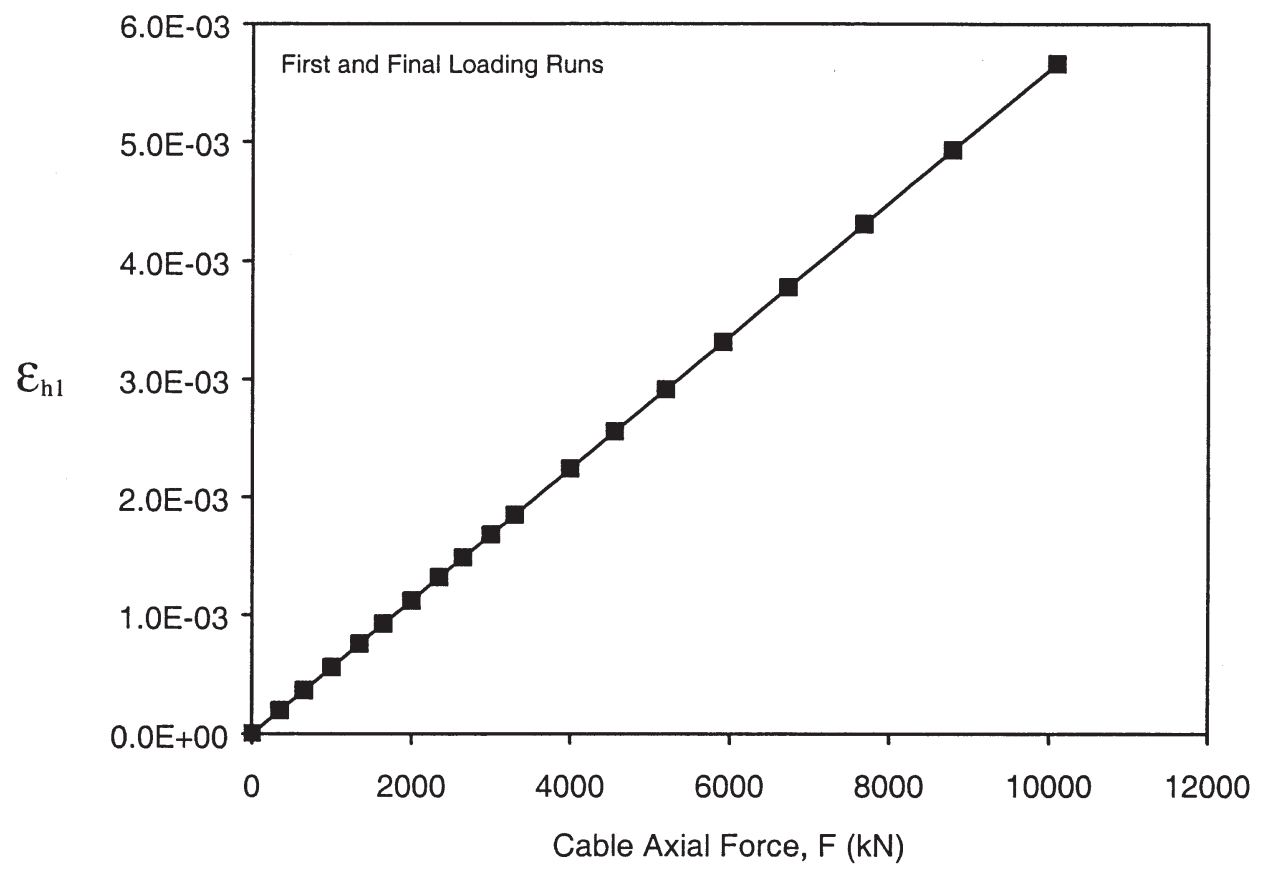

Fig. 11 Theoretical variations in the cable axial strain, $\varepsilon_{\mathrm{h} 1}$, with changes in the externally applied cable axial force, $F$, for both the first and final loading runs, based on the rigorous method 


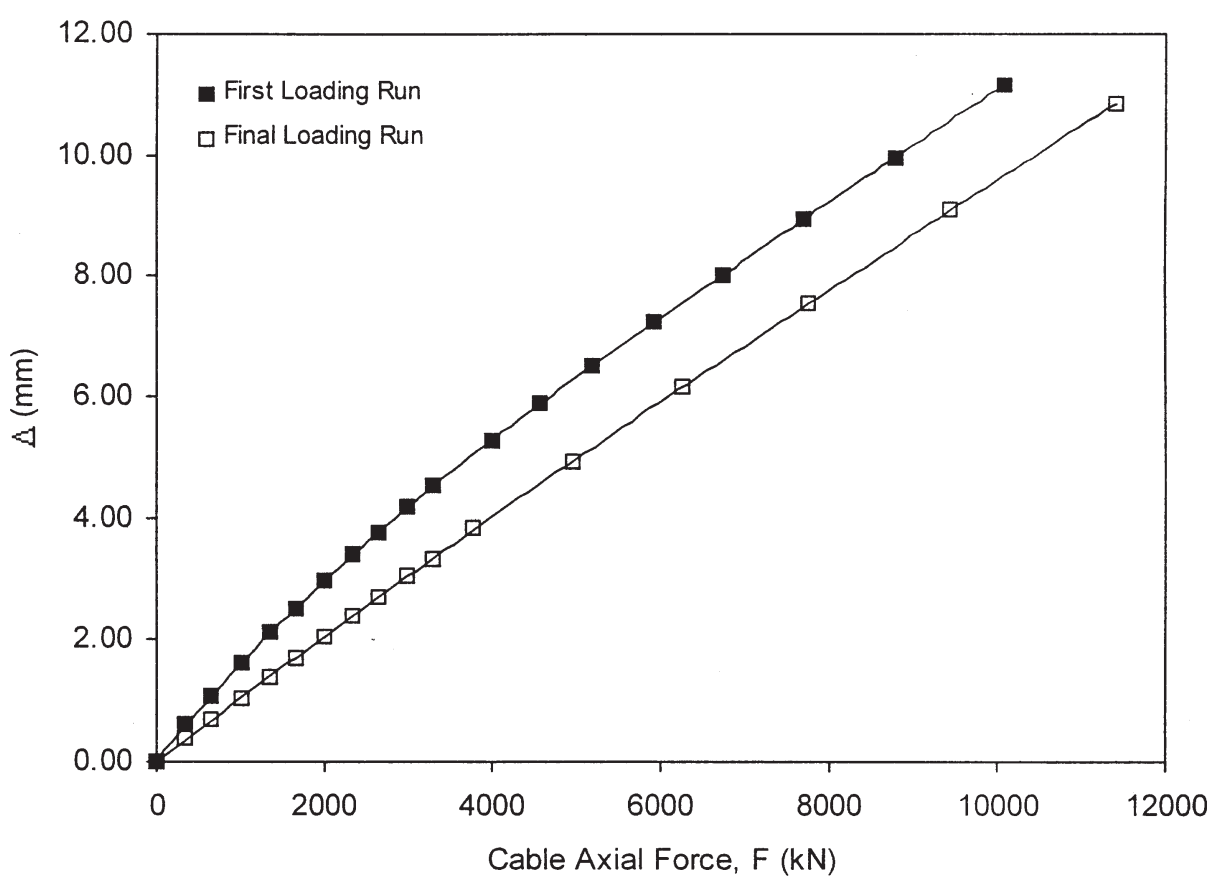

Fig. 12 Theoretical variations in $\Delta$ with changes in the externally applied cable axial force, $F$, for both the first and final loading runs, based on the rigorous method

\section{DISCUSSION}

Figure 8 shows the theoretical predictions, based on both the simplified and rigorous methods, along with the experimental data for the first and final loading runs, with the experimental data extrapolated to other regions of axial force, $F$, for which no test data are available. The correlations between the theoretical and experimental data, where available, are very encouraging, and, at all levels of cable axial force, the match between the results based on both the simplified and rigorous approaches is encouraging, reinforcing the fact that the influence of a number of parameters ignored in the simplified approach, regarding the exact form of the $F$ versus $2 r$ plots, is sufficiently small to be ignored.

From Fig. 7 and Table 2 it is clear that there exist some rather significant differences between the experimentally obtained bending stiffnesses, $(E I)_{\text {cable }}$, for the first and final loading runs, the difference being a factor of 2.6. This difference is believed to be due to the gradual nature of the interwire bedding-in, owing to the prestretching of the cable, and, as such, the helically wound cables may need (depending upon their construction) a very lengthy period of working-in for their internal structure to become reasonably stabilized [17]. During this period, the bending stiffness will change in a complex way owing to its sensitivity to the degree of bedding-in.

Comparing the prediction of the full-slip plane-section bending stiffness, $(E I)_{\text {full-slip }}$, with the experimentally obtained one, $(E I)_{\text {cable }}$, for the final loading run shows a difference by a factor of 4 , with the experimentally determined value being 4 times less than the theoretically obtained full-slip plane-section bending stiffness. As regards the experimental results, unfortunately, the number of loading cycles (after the strand has been unwrapped from the drum) between the first and final loading runs is not known. Indeed, it is also not known as to whether the newly manufactured strand had been subjected to any initial bedding-in loading cycles prior to reeling it onto the drum. It is, on the other hand, known that the experimental data have been obtained from a new strand that has shortly after its manufacture had its lay disturbed (cf. the case when the strand is in a fairly straight condition) by reeling it onto rather too small a drum, giving rise to the pigtail effect exploited by the present authors: these may (at least partly) be the reasons for the difference found between the measured and predicted (plane-section) values of bending stiffness. This, however, should not distract attention from the fact that the present work does make it possible to obtain a much better estimate of the effective bending stiffness than was previously available.

\section{CONCLUSIONS}

Presented in this paper is a promising experimental method for obtaining the effective bending stiffness of a spiral strand, the reliable experimental determination of which, until now, had largely proven to be elusive. The previously available experimental data relating to the effective bending stiffness of a helically wound cable had invariably been too dependent upon the 
specific experimental technique employed. The experimental technique proposed is believed to be a significant step forward in measuring the in situ effective bending stiffness, for even very large diameter spiral strands, at reasonable cost and effort, involving minimal physical interface with the imposed strand deformations, with this having been, at least in some cases, a major obstacle in obtaining trustworthy test data.

\section{REFERENCES}

1 Raoof, M. and Huang, Y. P. Upper-bound prediction of cable damping under cyclic bending. J. Engng Mechanics, ASCE, 1991, 117(12), 2729-2747.

2 Raoof, M. and Huang, Y. P. Wire stress calculations in helical strands undergoing bending. Trans. ASME, J. Offshore Mechanics and Arctic Engng, August 1992, 114(3), 212-219.

3 Raoof, M. and Huang, Y. P. Free bending characteristics of axially preloaded spiral strands. Proc. Instn Civil Engrs, Structs and Buildings, November 1992, 94, 469-484.

4 Davies, T. J. Static, dynamic and fatigue characteristics of helical cables. PhD thesis, Loughborough University, 2000 .

5 Lanteigne, J. Theoretical estimation of the response of helically armoured cables to tension, torsion and bending. Trans. ASME, J. Appl. Mechanics, June 1985, 52, 423-432.

6 Costello, G. A. and Butson, G. J. Simplified bending theory for wire rope. J. Engng Mechanics Div., ASCE, April 1982, 108(EM2), 219-227.

7 Malinovsky, V. A. Bending stiffness of steel wire ropes. In Proceedings of Organisation pour International l'Etude de l'Endurance des Cables (OIPEEC) Round Table Conference, Delft, The Netherlands, 1993, pp. II35-II49.

8 Raoof, M. and Hobbs, R. E. The bending of spiral strands and armoured cables close to terminations. Trans. ASME, J. Energy Resources Technol., 1984, 106(3), 349-355.

9 Raoof, M. and Davies, T. J. Restrained bending characteristics of helical cables at terminations. In Proceedings of 3rd International Symposium on Cable Dynamics, University of Trondheim, Trondheim, Norway, August 1999, pp. 31-36.

10 Raoof, M. Free bending tests on large spiral strands. Proc. Instn Civil Engrs, Part II, December 1989, 87, 605-626.

11 Raoof, M. Free bending fatigue of axially preloaded spiral strands. J. Strain Analysis, 1992, 27(3), 127-136.

12 Love, A. E. H. A Treatise on the Mathematical Theory of Elasticity, 1944 (Dover Publications, New York).

13 Blanco, J. A. and Costello, G. A. Cylindrical constraint of helical springs. Trans. ASME, J. Appl. Mechanics, December 1974, 41, 1138-1140.

14 Hobbs, R. E. and Raoof, M. Interwire slippage and fatigue prediction in stranded cables for TLP tethers. In Behaviour of Offshore Structures (Eds C. Chryssostomidis and J. J. Connor), 1982, Vol. 2, pp. 77-99 (Hemisphere Publishing/ McGraw-Hill, New York); (Proceedings of 3rd International Conference on Behaviour of Offshore Structures, MIT, Cambridge, Massachusetts, 1982).

15 Raoof, M. Design recommendations for steel cables. Struct. Engng Rev., 1992, 4(3), 223-233.

16 Raoof, M. and Hobbs, R. E. Torsional stiffness and hysteresis in spiral strands. Proc. Instn Civil Engrs, Part II, December 1989, 87, 501-515.

17 Raoof, M. Comparison between the performance of newly manufactured and well-used spiral strands. Proc. Instn Civil Engrs, Part II, March 1990, 89, 103-120. 
